\title{
ANALISIS REALISASI ANGGARAN DAN RENCANA KERJA ANGGARAN SEKOLAH (RKAS) TAHUN ANGGARAN 2016 DAN 2017 PADA SMPIT AL-IZZAH KOTA SERANG
}

\author{
Khristina Sri Prihatin"1), Nopian ${ }^{2)}$ \\ Universitas Banten Jaya \\ Serang Indonesia
}

khristinsriprihatin@unbaja.ac.id',nopian@unbaja.ac.id²

\begin{abstract}
This study aimed to determine how the budget realization and work plan for the Al-Izzah Junior High School budget in Serang City for the period 2016 and 2017 and to determine the suitability of the RPP and its realization. In this study, researchers used quantitative research because the data of this study were taken from the plan data and the realization of the school budget in the form of numbers and then examined the correctness. The results of this study found that there were differences between the realization and the budget, such as spending deviations that were not in accordance with school budget allocations and expenditures were not reasonable with predetermined values. It was expected that every activity carried out by school requires an evaluation of the activity program to carry out activities in accordance with what was planned. In preparing the school budget work plan, it was necessary to pay attention to the types, objects and details of expenditure objects that would be needed so that the plan was achieved, and the budget format was required both for reports and realization in accordance with Standard Operating Procedures.
\end{abstract}

Keywords: Budget Work Plan, Budget Realization, School Budgeting

PENDAHULUAN

Penganggaran merupakan proses kegiatan atau proses penyusunan anggaran (budgeting). Budget ini merupakan rencana operasional yang dinyatakan secara kuantitatif dalam bentuk satuan uang yang digunakan sebagai pedoman dalam melaksanakan kegiatan lembaga dalam kurun waktu tertentu.
Menurut (Nanang Fattah dalam Abubakar, Taufani C. Kurniatun (Ed) (2013:258) Anggaran (budgeting) adalah suatu estimasi kerja untuk melihat hasil kinerja suatu karyawan. Perencanaan keuangan, termasuk di dalamnya adalah perencanaan pembelanjaan atau budgeting (anggaran), pada dasarnya merupakan suatu cara sistematis dan formal bagi manajemen untuk melaksanakan tanggung jawab yang 
meliputi aspek-aspek perencanaan, koordinasi dan pengawasan (planning, coordination and control).

Anggaran itu adalah sebagai alat perencanaan dan pengendalian untuk memotivasi karyawan, memperbaiki kinerja dan sikap karyawan, serta mengungkap peran anggaran dalam mengelola kekayaan sebuah organisasi dan berkeinginan memberikan pelayaan yang maksimal terhadap masyarakat tetapi sering terkendala oleh keterbatasan sumber daya yang dimiliki, maka anggaran memiliki fungsi dan peran penting. Anggaran dapat dikatakan juga sebagai pernyataan mengenai estimasi kinerja yang hendak dicapai selama periode tertentu dalam ukuran finansial.

Anggaran memiliki dua sisi penerimaan dan pengeluaran yang menggambarkan perolehan atau besarnya dana yang diterima oleh lembaga dari setiap sumber dana, misalnya dari pemerintah, masyarakat, orang tua peserta didik dan sumber lainnya. Sedangkan sisi pengeluaran menggambarkan besarnya biaya yang yang harus dikeluarkan untuk tiap komponen program. Istilah-istilah yang lazim untuk pengeluaran anggaran adalah dana pembangunan (recurrent expenditure and capital expenditure), dalam bidang keuangan suatu perusahaan, instansi, sekolah, universitas dan lain-lain.

Menurut Deddi Nordiawan dan Ayuningtyas (2010 : 100) fungsi penganggaran sendiri bagi sekolah adalah sebagai alat untuk perencanaan dan pengendalian manajemen dalam mengarahkan suatu lembaga menempatkan organisasi dalam posisi yang kuat atau lemah. Anggaran jugadapat berfungsi sebagai tolak ukur keberhasilan suatu organisasi dalam mencapai sasaran yang telah ditetapkan. Selain itu anggaran juga dapat dijadikan alat untuk mempengaruhi dan memotivasi pimpinan atau manajer dan karyawan untuk bertindak efisien dalam mencapai sasaran lembaga. Anggaran sebagai alat efisiensi merupakan fungsi yang paling esensial dalam pengendalian. Dari segi pengendalian jumlah anggaran yang didasarkan atas angka-angka yang standar dibandingkan dengan realisasi biaya yang melebihi atau kurang, dapat dianalisis ada tidaknya pemborosan atau penghematan.

Menurut Nanang Fatah (2009 : 47) Anggaran sebagai pedoman pelaksanaan pekerjaan, artinya sebelum bekerja dilaksanakan terlebih dahulu mendapatkan persetujuan yang berwenang (terutama dalam hal keuangan). Pekerjaan disetujui untuk dilaksanakan bila ada anggarannya 
atau tidak menyimpang dari anggaran. Membeli kendaraan tidak akan disetujui bila tidak ada anggarannya atau membeli bahan lebih mahal dari anggaran juga tidak akan disetujui, sebab semua itu akan membuat suatu anggaran menjadi minus.

Menurut M. Nafarin (2013 : 29) anggaran dibuat berdasarkan taksiran dan anggapan sehingga mengandung unsur ketidak pastian, menyusun anggaran yang cermat memerlukan waktu, uang, dan tenaga yang tidak sedikit sehingga tidak semua perusahaan,institusi, sekolah mempu menyusun anggaran secara lengkap (komprehensif) dan akurat. Suatu anggaran, baik perusahaan, instansi maupun sekolah perlu perencanaan yang matang serta pemikiran yang mendalam dalam artian perlu pertimbangan yang benar-benar berpotensi baik untuk kegiatan-kegiatan yang akan dilaksanakan dimasa yang akan datang.

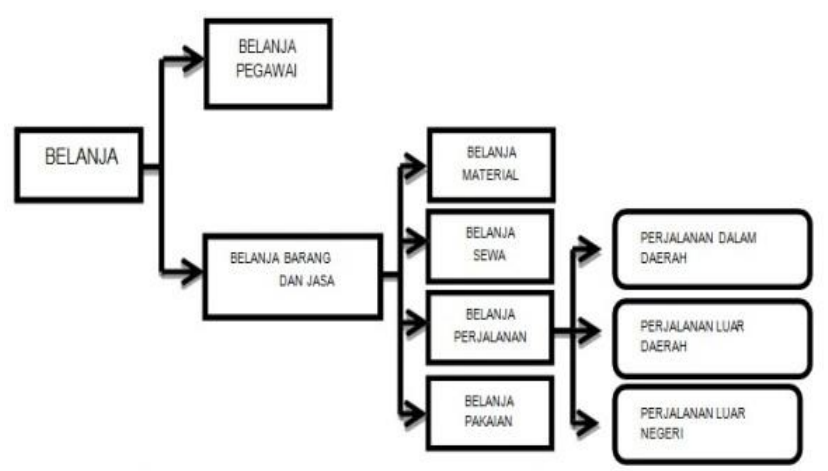

Gambar 1 Struktur Anggaran Belanja

Fakta yang terjadi di sekolah SMPIT Al-Izzah adalah setiap rencana anggaran yang dibuat dalam 1 (satu) tahun, tidak sesuai dengan realisasi anggaran yang dibuat, sehingga rencana anggaran yang dibuat sepertinya tidak terpakai, hanya wacana dan hanya sebatas sebagai laporan ketika pengganggaran dibuat dan diminta oleh pihak owner sekolah. Ketidaksesuaian antara rencana dan realisasi anggaran ini sudah lama terjadi di SMPIT Al-Izzah sehingga mendorong peneliti untuk bisa mengungkap dan mencari penyebab atas anggaran yang tidak sesuai dengan rencana anggaran yang sudah dibuat.

Realisasi anggaran yang ada dan sudah terjadi, perlu dilaporkan dan di pertanggung jawabkan dengan membuatkan bukti-bukti transaksi kegiatan yang dilaksanakan pada setiap tahun ketahuan, laporan pertanggung jawaban ini harus sesuai dengan realisasi anggarannya yang telah ditetapkan dan harus menghasilkan saldo nol. Maka dalam masalah ini perlu dilakukan penelitian sehingga apabila laporan anggaran dapat diperbaiki merupakan keuntungan jika ini diteliti akan memberikan perkembangan keuangan yang positif kepada instansi maupun sekolah dan memberikan ilmu baru dalam pembuatan anggaran jika ada kekurangan atau mengalami selisih anggaran. Kerugiannya apabila tidak adanya penelitian terhadap perbaikan 
kinerja laporan keuangan maka akan berdampak tidak sesuainya antara perencanaan dan realisasi anggaran yang secara terus menurus berulang setiap tahun. Realisasi adalah suatu proses untuk menjadikan sesuatu rencana menjadi nyata. Keakuratan penyusunan anggaran dapat ditentukan dengan membandingkan angkaangka aktual dengan angka-angka dalam anggaran.

Perbedaan antara angka budget (anggaran) dengan realisasi ini disebut penyimpangan atau variance (perbedaan). Kalau kita anggap anggaran itu sudah benar dan akurat maka secara prinsip kita harus mengusahakan agar realisasi harus sama dengan anggaran. Artinya penyimpangan ini diusahakan nol atau sesedikit mungkin. Karena anggaran merupakan sesuatu yang ideal yang harus dicapai pada waktu anggaran itu berjalan.

Sedangkan menurut Indra Bastian (2005 : 139) Laporan Realisasi Anggaran adalah laporan yang menyajikan informasi realisasi pendapatan, belanja, transafer, surplus/defisit, dan pembiayaan, yang masing-masing dipergunakan dengan anggarannya dalam satu periode". Yang terjadi di SMPIT Al-Izzah laporan anggaran antara realisasi dan rencananya sudah tentu tidak akan sejalan dan terjadi kesesuaian dari apa yang diharapkan.
Adapun terkait dengan perkiraan data keuangan apabila terjadi selisih atau ketidaksesuaian maka harus dilakukan penelusuran terhadap fakta keuangan yang terjadi.

Namun sebagaimana yang namanya taksiran maka tidak selalu anggaran itu benar dan tidak juga selalu sama dengan realisasi. Untuk mengetahui lebih pasti maka setiap pos biaya-biaya harus ditelusuri sampai ke akarnya agar menemukan titik masalah yang terjadi.

\section{METODE PENELITIAN}

Penelitian ini menggunakan metode penelitian kuantitatif karena penelitian ini dilakukan untuk mengetahui analisa yang dilakukan antara variabel bebas yakni realisasi anggaran dan variabel terikat yakni rencana kerja anggaran, dimana penelitian ini mengambil data dari data rencana dan realisasi anggaran sekolah yang berbentuk angka dan kemudian diuji kebenarannya.

Penelitian ini dilakukan di SMPIT Al- Izzah yang beralamat Jalan Tubagus Raya Pabuaran Unyur Kota Serang dengan mengambil sampel data keuangan realisasi anggaran sekolah (RKAS) dari tahun 2016 sampai dengan tahun 2017. 


\section{TEKNIK PENGUMPULAN DATA}

Pengumpulan data dalam penelitian ini menggunakan beberapa metode agar diperoleh data yang lengkap. Metode yang digunakan untuk mengumpulkan data dalam penelitian ini adalah dokumentasi dan wawancara.

Metode dokumentasi yang di dapat oleh peneliti berupa : a) Anggaran tahun 2016; b) Anggaran tahun 2017; c) Laporan realisasi anggaran tahun anggaran 2016 dan d) Laporan rencana anggaran sekolah tahun 2016 sampai tahun 2017. Untuk metode wawancara peneliti melakukan wawancara dengan Bendahara Sekolah yang merangkap Bendahara dana BOS yang bernama Ibu Tika Madrika. Adapun pertanyaan yang disampaikan kepada bendahara sekolah sebagai berikut :

Tabel 1. Wawancara Realisasi Anggaran dan Rencana Anggaran

\begin{tabular}{lll}
\hline No. & \multicolumn{1}{c}{$\begin{array}{l}\text { Pertanyaan } \\
\text { Wawancara }\end{array}$} & Jawaban Wawancara \\
\hline 1. & Bagaimana \\
pengelolaan & - Karena anggaran sudah \\
anggaran belanja & $\begin{array}{l}\text { ditetapkan di awal } \\
\text { tahun ajaran (sesuai }\end{array}$ \\
yang nominalnya & biaya pendidikan / \\
harus sesuai yang & daftar ulang siswa), \\
telah ditetapkan? & maka kegiatan yang \\
Dan bagaimana jika & akan dilaksanakan \\
besarnya anggaran & harus menyesuaikan \\
belanja mengalami & dengan anggaran yang \\
kelebihan yang telah & ada, sehingga \\
dianggarkan? & meminimalisir defisit \\
& anggaran.
\end{tabular}

- Jika ada defisit anggaran maka akan ditanggulangi dari anggaran rutin yang surplus (yang masih ada sisa anggaran), artinya jika ada anggaran yang surplus dalam kegiatan 1 (satu) bulan maka disetorkan ke kas yayasan

2. Bagaimana pendapat - Anggaran yang defisit ibu, mengenai anggaran belanja bukan berarti baik, hanya saja memang yang di bawah dari itu baru perkiraan anggaran yang ditetapkan dalam yang kadang-kadang meleset dari rencana artian surplus, apakah ini dikatakan favorable (baik) atau sebaliknya? Dan untuk surplusnya diarahkan kemana, apakah ini masuk pendapatan atau untuk menutupi pos anggaran yang kekurangan dana? Jika iya apakah ini boleh sedangkan setiap pos sudah ada nominal tersendiri yang ditetapkan?

$$
\text { yang }
$$

ditetapkan

sebelumnya. Khusus

untuk dana-dana rutin

kadang mengalami

defisit dan juga

bahkan surplus,

tergantung dari

pengeluaran.

- Jika ada dana yang surplus dan ada juga dana yang defisit dalam 1 (satu) bulan itu boleh ditanggungulangi

oleh dana yang surplus, tetapi itu hanya diperbolehkan jangka waktunya dalam satu bulan berjalan, dan kelebihan dana yang masih surplus maka akan diserahkan kembali ke unit pelayanan keuangan. 


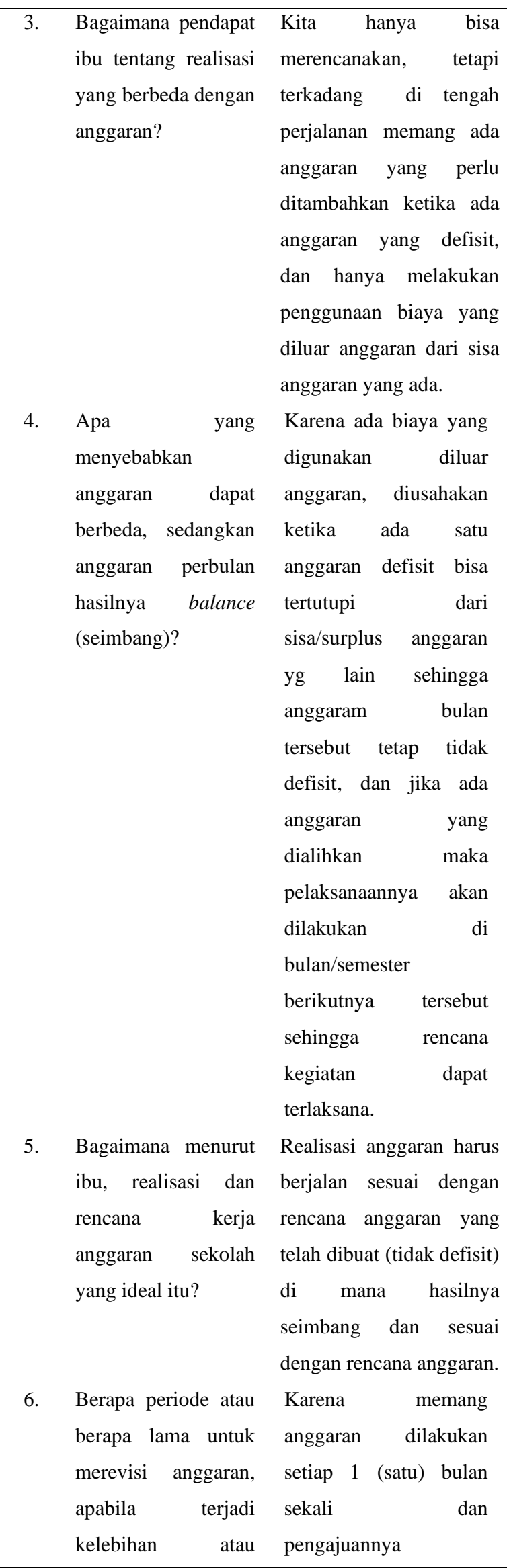

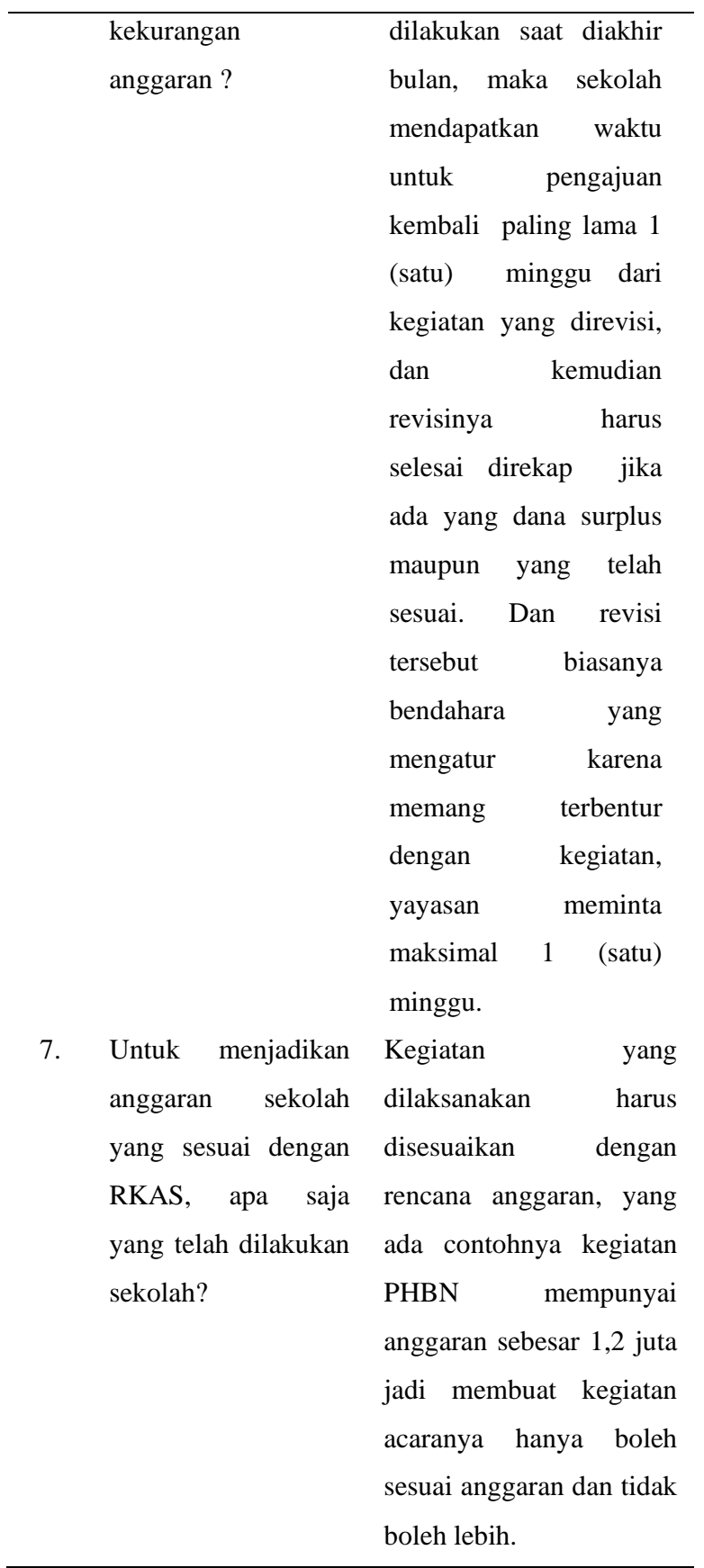

\section{TEKNIK ANALISIS DATA}

Untuk mengetahui bagaimana pengelolaan keuangan sekolah di SMPIT Al-Izzah Kota Serang, peneliti menganalisis data baik data primer maupun sekunder. Data primer yakni yang diperoleh dari hasil wawamcara ke sekolah 
dan data sekuder adalah data RKAS dan laporan realisasi angaran sekolah. Peneliti menganalisis data yang diperoleh menggunakan aplikasi Microsoft Office (Excel) dan menggunakan rumus sederhana yaitu Vlookup, Sum, dan Min dan yang lainnya untuk mengetahui bagaimana proses penyusunan RKAS, alokasi sumber dana, perimbangan anggaran tiap bidang tugas, serta realisasi anggaran dalam pengelolaan sekolah di SMPIT Al-Izzah Kota Serang.

Penyajian data penelitian dapat berupa laporan diskriptif, yaitu menjelaskan bagaimana pengelolaan RKAS di SMPIT Al-Izzah Kota Serang serta realisasi anggaran sekolah yang sudah dilaksanakan, data tabel yang dapat menggambarkan alokasi sumber dana dan perimbangan besarnya anggaran tiap bidang tugas di SMPIT Al-Izzah serta penemuan-penemuan pengolahan data dalam laporan realisasi anggaran yang dilakukan sekolah.

Laporan yang dilakukan secara periodik harus disiapkan untuk membandingkan biaya aktual dengan biaya yang dianggarkan. Laporan ini dapat disiapkan secara bulanan (ini yang biasanya terjadi), kuartalan, enam bulan, dan tahunan. Laporan anggaran harus dimulai dengan poin-poin utama dan ringkasan. Laporan harus mudah dimengerti, jelas, dan singkat. Informasi harus diperbarui sesuai dengan perubahan situasi.

Informasi laporan harus sesuai dengan jadwal dan bila laporan tertunda, harus disediakan laporan pendek sebagai pengganti. Revisi anggaran terkadang dibutuhkan karena adanya perubahan tujuan, proses baru, perubahan lingkungan ekonomi, dank arena kesalahan. Dalam revisi anggaran harus ada penjelasan naratif.

Adapun menurut Jae K. Shim, Joel G. Siagel. (200 : 26) Laporan kinerja terhadap anggaran (performance to budget) harus termasuk anggaran, aktual, dan varians, berdasarkan departemen untuk bulan dan tahun yang bersangkutan. Varians dapat dinyatakan dalam bentuk dolar/rupiah atau persentase. Laporan anggaran harus meliputi perbandingan antara angka-angka anggaran dengan angka aktualnya berikut penjelasan atas perbedaan yang terjadi”.

Menurut Sofyan Syafri Harahap (2001 : 223) juga mengungkapkan kalau kita anggap budget (anggaran) itu sudah benar dan akurat maka secara prinsip kita harus agar mengusahakan realisasi harus sama dengan benar. Artinya penyimpangan diusahakan nol atau 
sesedikit mungkin dan penyimpangan harus dianalisis penyebab".

Tabel 2. Contoh Format Laporan Analisis Penyimpangan

\begin{tabular}{|l|l|l|l|l|l|}
\hline No & Keterangan & $\begin{array}{c}\text { Bu } \\
\text { dg } \\
\text { et }\end{array}$ & Realisasi & $\begin{array}{c}\text { Selisih/ } \\
\text { Variance }\end{array}$ & Keterangan \\
\hline 1. & & & & & \\
\hline 2. & & & & & \\
\hline \multicolumn{5}{|c|}{ Sumber : Sofyan Syafri Harahap }
\end{tabular}
$(2001: 225)$

Dan hasil analisis akan disajikan dalam tabel analisis penyimpangan anggaran tahun 2016. Untuk perhitungan persentase $\mathrm{H}$. Muhaimin,
Suti'ah, dan Sugeng Listyo Prabowo (2009:414) mengatakan bahwa perhitungan persentase pencapaian rencana tingkat capaian dilakukan sebagai berikut :"

$\frac{\text { Persentase pencapaian }}{\text { Rencana tingkat capaian }}=\frac{\text { Realisasi }}{\text { Rencana }} \times 100 \%$

\section{HASIL PENELITIAN DAN}

\section{PEMBAHASAN}

Berikut analisis anggaran dan realisasi disajikan dalam bentuk tabel berikut :

Tabel 3 SEKOLAH MENENGAH PERTAMA AL-IZZAH

ANALISIS PENYIMPANGAN

\begin{tabular}{|c|c|c|c|c|c|c|c|c|}
\hline \multicolumn{9}{|c|}{ TAHUN 2016} \\
\hline $\mathrm{NO}$ & BULAN & & BUDGET & & EALISASI & VARIANCE & PERSENTASE & KETERANGAN \\
\hline 1 & JANUARI & $\mathrm{Rp}$ & $96,893,000$ & $\mathrm{Rp}$ & $96,879,400$ & 13600 & $100 \%$ & \\
\hline 2 & FEBRUARI & $\mathrm{Rp}$ & $63,873,750$ & $\mathrm{Rp}$ & $63,835,010$ & 38740 & $100 \%$ & \\
\hline 3 & MARET & $\mathrm{Rp}$ & $71,227,000$ & $\mathrm{Rp}$ & $71,214,000$ & 13000 & $100 \%$ & \\
\hline 4 & APRIL & $\mathrm{Rp}$ & $54,504,500$ & $\mathrm{Rp}$ & $39,920,750$ & 14583750 & $73 \%$ & $\begin{array}{c}\text { Kegiatan (UN) yang tertunda akan dilaksanakan } \\
\text { dibulan Juni } 2016\end{array}$ \\
\hline 5 & MEI & $\mathrm{Rp}$ & $74,326,500$ & $\mathrm{Rp}$ & $74,306,800$ & 19700 & $100 \%$ & \\
\hline 6 & JUNI & $\mathrm{Rp}$ & $53,206,500$ & $\mathrm{Rp}$ & $53,171,600$ & 34900 & $100 \%$ & \\
\hline 7 & JULI & $\mathrm{Rp}$ & $280,445,800$ & $\mathrm{Rp}$ & $280,360,100$ & 85700 & $100 \%$ & \\
\hline 8 & AGUSTUS & $\mathrm{Rp}$ & $92,008,950$ & Rp & $91,995,000$ & 13950 & $100 \%$ & \\
\hline 9 & SEPTEMBER & $\mathrm{Rp}$ & $109,083,750$ & $\mathrm{Rp}$ & $108,801,200$ & 282550 & $100 \%$ & \\
\hline 10 & OKTOBER & $\mathrm{Rp}$ & $88,309,750$ & $\mathrm{Rp}$ & $87,026,100$ & 1283650 & $99 \%$ & Kegiatan PHBN yang tidak terlaksana \\
\hline 11 & NOVEMBER & $\mathrm{Rp}$ & $38,475,750$ & $\mathrm{Rp}$ & $38,450,700$ & 25050 & $100 \%$ & \\
\hline 12 & DESEMBER & $\mathrm{Rp}$ & $73,806,050$ & Rp & $73,776,800$ & 29250 & $100 \%$ & \\
\hline & Total & $\mathrm{Rp}$ & $1,096,161,300$ & $\mathrm{Rp}$ & $1,079,737,460$ & 16423840 & $99 \%$ & \\
\hline
\end{tabular}

Berdasarkan tabel 3 diatas menunjukkan hasil analisis selama satu tahun yaitu tahun 2016 ada dua kegiatan yang tidak sampai 100\% dikarenakan ada kegiatan UN (ujian nasional) yang tertunda dan akan dilaksanakan di bulan Juni 2016 dan kegiatan PHBN yang tidak terlaksana perlu kita ketahui bahwa anggaran yang dibawah $100 \%$ itu tidak terlalu bagus dikarenakan menurut peneliti apa yang direncanakan maka itu yang harus direalisasikan atau dilaksanakan tidak boleh keluar dari rencana. Jika anggaran dibawa misal 
75\% tercapai itu juga tidak baik karena

penyusunan anggarannya kurang efektif.

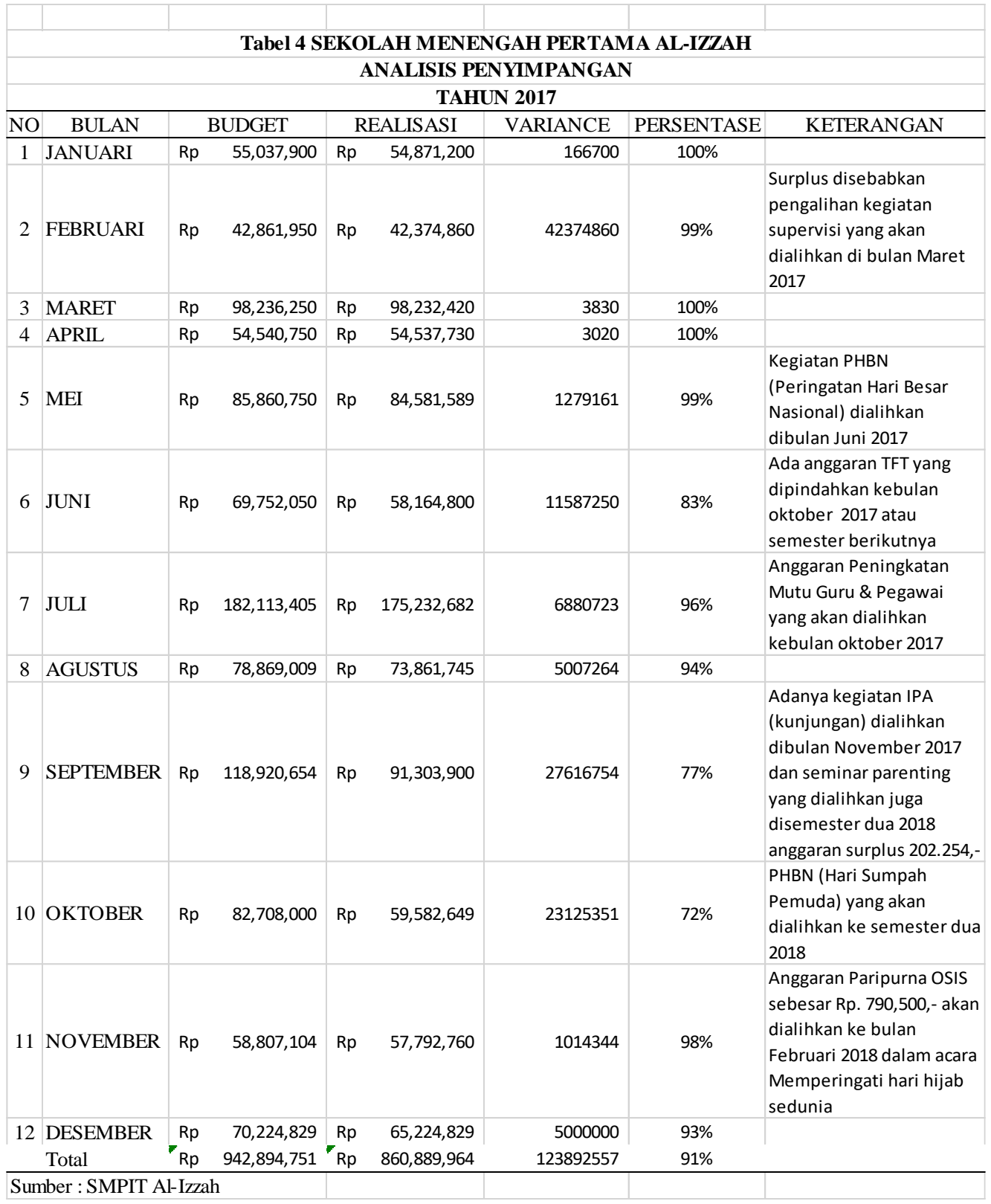

Berdasarkan tabel. 4 di atas ditunjukkan bahwa ada 10 (sepuluh) kegiatan yang tidak mencapai $100 \%$ karena adanya pengalihan anggaran ke bulan berikutnya atau semester dua berikut ini anggaran yang dialihkan atau yang tertunda :
1. Bulan Februari kegiatan supervisi dialihkan ke bulan maret 2017 sehingga anggaran di bulan Februari mengalami surplus sebesar Rp. 487.090,00

2. Bulan Mei kegiatan PHBN atau yang biasa kita sebut dengan Peringatan Hari 
Besar Nasional yang dialihkan ke bulan Juni 2017.

3. Bulan Juni kegiatan TFT (Training For Teacher) yang diikuti seluruh guru dan pegawai yang dialihkan ke bulan Oktober 2017.

4. Bulan Juli Peningkatan Mutu Guru dan Pegawai yang akan dialihkan ke bulan Oktober 2017.

5. Bulan September kegiatan IPA (Ilmu Pengetahuan Alam) kunjungan dialihkan di bulan November 2017 dan seminar parenting yang dialihkan juga di semester 2 (dua) 2018 anggaran surplus Rp. $202.254,00$

6. Bulan Oktober kegiatan PHBN (Hari Sumpah Pemuda) yang akan dialihkan ke semester 2 (dua) 2018

7. Bulan November anggaran paripurna OSIS sebesar 790.500,00 yang akan dialihkan ke bulan Februari 2019 dalam acara memperingati hijab sedunia. 


\begin{tabular}{|c|c|c|c|c|c|c|c|}
\hline & & $\begin{array}{r}\text { Tabel } 5 \text { SMP ISLAI } \\
\text { LAPORAN P } \\
\text { TAHUN }\end{array}$ & $\begin{array}{l}\text { TER } \\
\text { IYIM } \\
\text { ARA }\end{array}$ & $\begin{array}{l}\text { DU AL-IZZA } \\
\text { NGAN } \\
\text { O16 }\end{array}$ & & & \\
\hline No & BULAN & PERKIRAAN & & UDGET & & EALISASI & VARIANCE \\
\hline 1 & & Peningkatan Mutu Guru & $\mathrm{Rp}$ & 850,000 & $\mathrm{Rp}$ & $1,000,000$ & $(150000)$ \\
\hline 2 & & Konsumsi Tamu & $\mathrm{Rp}$ & 680,000 & $\mathrm{Rp}$ & 794,300 & (114300) \\
\hline 3 & & Banten SIT Championship & Rp & $4,250,000$ & $\mathrm{Rp}$ & $8,168,600$ & $(3918600)$ \\
\hline 4 & & Lain-lain & & & $\mathbf{R p}$ & 587,000 & $(587000)$ \\
\hline 5 & & Fotocopy kegiatan sekolah & Rp & 425,000 & $\mathrm{Rp}$ & 691,460 & $(266460)$ \\
\hline 6 & & Pelepasan Baju Wisuda & & $10,200,000$ & $\mathrm{Rp}$ & $10,476,800$ & $(276800)$ \\
\hline 7 & & Lain-lain & & & $\mathrm{Rp}$ & $3,094,500$ & $(3094500)$ \\
\hline 8 & & Peningkatan Mutu Guru & $\mathrm{Rp}$ & 850,000 & $\mathrm{Rp}$ & $1,500,000$ & $(650000)$ \\
\hline 9 & & Morning Tea & $\mathrm{Rp}$ & 612,000 & $\mathrm{Rp}$ & 754,000 & $(142000)$ \\
\hline 10 & & Fotocopy kegiatan sekolah & $\mathrm{Rp}$ & 425,000 & $\mathrm{Rp}$ & $1,668,940$ & $(1243940)$ \\
\hline 11 & & Lain-lain & & & $\mathrm{Rp}$ & $2,524,400$ & $(2524400)$ \\
\hline 12 & & Fotocopy kegiatan sekolah & $\mathrm{Rp}$ & 425,000 & $\mathrm{Rp}$ & $1,048,900$ & $(623900)$ \\
\hline 13 & & Transportasi umum & Rp & 510,000 & $\mathbf{R p}$ & 660,000 & $(150000)$ \\
\hline 14 & & Lain-lain & & & $\mathrm{Rp}$ & $3,535,650$ & $(3535650)$ \\
\hline 15 & & Rapat Bulanan & Rp & 510,000 & $\mathrm{Rp}$ & $1,200,000$ & $(690000)$ \\
\hline 16 & & Konsumsi Tamu & Rp & 680,000 & $\mathrm{Rp}$ & 862,200 & $(182200)$ \\
\hline 17 & & Fotocopy kegiatan sekolah & $\mathrm{Rp}$ & 425,000 & $\mathrm{Rp}$ & 761,800 & $(336800)$ \\
\hline 18 & & PHBI & Rp & $1,700,000$ & Rp & $1,900,000$ & $(200000)$ \\
\hline 19 & & Lain-lain & & & $\mathrm{Rp}$ & $5,730,800$ & $(5730800)$ \\
\hline 20 & & The best student & Rp & 255,000 & $\mathrm{Rp}$ & 720,000 & $(465000)$ \\
\hline 21 & & Lain-lain & & & $\mathrm{Rp}$ & $9,129,000$ & (9129000) \\
\hline 22 & & Alat Tulis KBM & Rp & $3,400,000$ & $\mathrm{Rp}$ & $5,303,000$ & $(1903000)$ \\
\hline 23 & & Rapat Bulanan & $\mathrm{Rp}$ & 573,750 & $\mathrm{Rp}$ & $1,168,000$ & $(594250)$ \\
\hline 24 & & Administrasi TU \& Pelaporan & Rp & 425,000 & $\mathbf{R p}$ & 845,000 & $(420000)$ \\
\hline 25 & & Fotocopy kegiatan sekolah & $\mathrm{Rp}$ & 425,000 & $\mathrm{Rp}$ & 638,300 & $(213300)$ \\
\hline 26 & & Pengadaan rapot & $\mathrm{Rp}$ & $4,675,000$ & Rp & $7,960,000$ & $(3285000)$ \\
\hline 27 & & UKS & $\mathbf{R p}$ & 612,000 & $\mathbf{R p}$ & $1,000,000$ & $(388000)$ \\
\hline 28 & & Pengadaan Sarana \& Prasarana awal semester & Rp & $6,034,150$ & Rp & $7,000,000$ & $(965850)$ \\
\hline 29 & & Meja \& kursi guru & Rp & $8,500,000$ & $\mathrm{Rp}$ & $8,650,000$ & $(150000)$ \\
\hline 30 & & Lain-lain & & & $\mathrm{Rp}$ & $7,743,000$ & $(7743000)$ \\
\hline 31 & & Administrasi TU \& Pelaporan & $\mathrm{Rp}$ & 425,000 & $\mathrm{Rp}$ & 619,400 & $(194400)$ \\
\hline 32 & & Fotocopy kegiatan sekolah & $\mathrm{Rp}$ & 425,000 & Rp & 787,000 & (362000) \\
\hline 33 & & Lain-lain & & & Rp & $7,644,400$ & $(7644400)$ \\
\hline 34 & & Konsumsi Tamu & $\mathrm{Rp}$ & 680,000 & $\mathrm{Rp}$ & $1,076,700$ & (396700) \\
\hline 35 & & Morning Tea & $R p$ & 612,000 & Rp & $1,620,000$ & $(1008000)$ \\
\hline 36 & & Fotocopy kegiatan sekolah & $\mathrm{Rp}$ & 425,000 & $\mathrm{Rp}$ & $2,006,800$ & $(1581800)$ \\
\hline 37 & & Lain-lain & & & Rp & $1,754,000$ & $(1754000)$ \\
\hline 38 & & Peningkatan Mutu guru & $\mathrm{Rp}$ & 722,500 & Rp & 850,000 & $(127500)$ \\
\hline 39 & & Administrasi TU \& Pelaporan & $\mathrm{Rp}$ & 425,000 & $\mathrm{Rp}$ & 665,000 & $(240000)$ \\
\hline 40 & & Fotocopy kegiatan sekolah & $\mathrm{Rp}$ & 425,000 & Rp & 871,900 & $(446900)$ \\
\hline 41 & & Perawatan mobil inventaris & $\mathrm{Rp}$ & 850,000 & $\mathrm{Rp}$ & $1,895,000$ & $(1045000)$ \\
\hline 42 & & Lain-lain & & & $\mathrm{Rp}$ & $1,481,700$ & $(1481700)$ \\
\hline 43 & & Administrasi TU \& Pelaporan & $\mathrm{Rp}$ & 425,000 & $\mathrm{Rp}$ & 660,000 & $(235000)$ \\
\hline 44 & & Konsumsi Tamu & $\mathrm{Rp}$ & 680,000 & $\mathrm{Rp}$ & 954,200 & $(274200)$ \\
\hline 45 & & Morning Tea & $\mathrm{Rp}$ & 612,000 & $\mathrm{Rp}$ & 840,000 & (228000) \\
\hline 46 & & Fotocopy kegiatan sekolah & $\mathrm{Rp}$ & 425,000 & Rp & 808,500 & (383500) \\
\hline 47 & & Lain-lain & & & $\mathrm{Rp}$ & 2,933,000 & $(2933000)$ \\
\hline 48 & & The Best Student & $\mathrm{Rp}$ & $1,020,000$ & $\mathrm{Rp}$ & $1,440,000$ & (420000) \\
\hline 49 & & Rapat Bulanan & $\mathrm{Rp}$ & 573,750 & Rp & $1,212,000$ & $(638250)$ \\
\hline 50 & & Administrasi TU \& Pelaporan & $\mathrm{Rp}$ & 425,000 & $\mathrm{Rp}$ & 645,000 & $(220000)$ \\
\hline 51 & & Lain-lain & & & Rp & $4,817,500$ & $(4817500)$ \\
\hline & & $\begin{array}{c}\text { Total Defisit } 2016 \\
\text { Persentase penyimpangan }\end{array}$ & $\mathrm{Rp}$ & $56,592,150$ & $\mathrm{Rp}$ & $\begin{array}{l}132,697,750 \\
234 \%\end{array}$ & (76105600) \\
\hline
\end{tabular}

Berdasarkan tabel. 5 di atas menunjukkan akumulasi penyimpangan (pemakaian dana dibelanjakan untuk kegiatan yang berbeda) berikut peneliti menjelaskan penyimpangan pada tahun 2016. Penyimpangan pada tahun 2016 sebesar 134\% atau sekitar Rp. 76.105.600,00 dalam penyimpangan ini perlu kita beri garis bawah karena penyimpangan bukan yang negatif hanya saja anggaran yang ada dibelanjakan untuk kegiatan yang berbeda dan untuk anggaran yang $100 \%$ tercapai belum tentu bagus karena ada dana yang yang ditalangkan/dipakai dahulu untuk kegiatan yang lain dan jika kita berpikir kegiatan yang tidak mencapai 100\% adalah tidak baik itu salah karena menurut Sofyan Syafri Harahap (2001 : 225) dalam buku 
Budgeting Peranggaran menyebutkan April 2016 persentase pencapaian kerja

bahwa dalam hal biaya, atau cost maka jika biaya realisasi lebih besar dari pada budget (anggaran) maka dianggap tidak menguntungkan (unfavorable). Sebaliknya jika realisasi lebih rendah dari (budget) anggaran maka dianggap menguntungkan atau baik (favorable). Sebagai contoh bulan $73 \%$ ini dana digunakan sangat efektif karena anggaran yang ada terpakai hanya $73 \%$. 


\begin{tabular}{|c|c|c|c|c|c|c|c|}
\hline \multirow{2}{*}{$\frac{\text { No }}{1}$} & \multirow[t]{2}{*}{ BULAN } & \multirow{2}{*}{$\begin{array}{l}\text { PERKIRAAN } \\
\text { Banten SIT Championship }\end{array}$} & \multicolumn{2}{|c|}{ BUDGET } & \multicolumn{2}{|c|}{ REALISASI } & \multirow{2}{*}{$\frac{\text { VARIANCE }}{(2004200)}$} \\
\hline & & & $\mathrm{Rp}$ & $4,896,000$ & $\mathrm{Rp}$ & $6,900,200$ & \\
\hline 2 & & Rapat Bulanan & $\mathrm{Rp}$ & 573,750 & $\mathrm{Rp}$ & $1,015,000$ & (441250) \\
\hline 3 & & Fotocopy kegiatan sekolah & $\mathrm{Rp}$ & 425,000 & $\mathrm{Rp}$ & $1,191,400$ & $(766400)$ \\
\hline 4 & & Transportasi kegiatan siswa dan guru & $\mathrm{Rp}$ & 552,500 & $\mathrm{Rp}$ & 825,000 & (272500) \\
\hline 5 & & Lain-lain & & & $\mathrm{Rp}$ & $1,555,000$ & $(1555000)$ \\
\hline 6 & & Publikasi apresiasi kegiatan siswa & $\mathrm{Rp}$ & 979,200 & $\mathrm{Rp}$ & $2,075,000$ & $(1095800)$ \\
\hline 7 & & Fotocopy kegiatan sekolah & $\mathrm{Rp}$ & 425,000 & $\mathrm{Rp}$ & 943,180 & $(518180)$ \\
\hline 8 & & Lain-lain & & & $\mathrm{Rp}$ & 762,000 & $(762000)$ \\
\hline 9 & & Administrasi TU \& Pelaporan & $\mathrm{Rp}$ & 425,000 & $\mathrm{Rp}$ & $1,735,000$ & $(1310000)$ \\
\hline 10 & & Konsumsi Tamu & $\mathrm{Rp}$ & 680,000 & $\mathrm{Rp}$ & 912,200 & $(232200)$ \\
\hline 11 & & Fotocopy kegiatan sekolah & $\mathrm{Rp}$ & 425,000 & $\mathrm{Rp}$ & 647,080 & (222080) \\
\hline 12 & & Lain-lain & & & $\mathrm{Rp}$ & $1,058,480$ & $(1058480)$ \\
\hline 13 & & Konsumsi Pembinaan Yayasan & $\mathrm{Rp}$ & 500,000 & $\mathrm{Rp}$ & $1,129,000$ & $(629000)$ \\
\hline 14 & & Fotocopy kegiatan sekolah & $\mathrm{Rp}$ & 425,000 & $\mathrm{Rp}$ & $1,685,730$ & (1260730) \\
\hline 15 & & Transportasi umum & $\mathrm{Rp}$ & 680,000 & $\mathrm{Rp}$ & 875,000 & $(195000)$ \\
\hline 16 & & Kegiatan Lomba & $\mathrm{Rp}$ & $1,275,000$ & $\mathrm{Rp}$ & $1,845,000$ & $(570000)$ \\
\hline 17 & & Pelepasan siswa Kelas 9 & $\mathrm{Rp} 2$ & $6,775,000$ & $\mathrm{Rp}$ & $27,462,200$ & $(687200)$ \\
\hline 18 & & Rapat Bulanan & $\mathrm{Rp}$ & 573,750 & $\mathrm{Rp}$ & $1,286,100$ & $(712350)$ \\
\hline 19 & & Fotocopy kegiatan sekolah & $\mathrm{Rp}$ & 425,000 & $\mathrm{Rp}$ & $1,140,400$ & $(715400)$ \\
\hline 20 & & Lain-lain & & & $\mathrm{Rp}$ & $1,275,016$ & (1275016) \\
\hline 21 & & The Best Teacher & $\mathrm{Rp}$ & 297,500 & $\mathrm{Rp}$ & $1,600,000$ & $(1302500)$ \\
\hline 22 & & Sanlat & $\mathrm{Rp}$ & $0,036,800$ & $\mathrm{Rp}$ & $10,511,800$ & $(475000)$ \\
\hline 23 & & Transportasi kegiatan siswa dan guru & $\mathrm{Rp}$ & 552,500 & $\mathrm{Rp}$ & $1,655,000$ & $(1102500)$ \\
\hline 24 & & Lain-lain & & & $\mathrm{Rp}$ & 960,000 & (960000) \\
\hline 25 & & Pelatihan /memenuhi undangan dinas/instansi & $\mathrm{Rp}$ & 861,050 & $\mathrm{Rp}$ & $2,250,000$ & $(1388950)$ \\
\hline 26 & & Alat Tulis KBM (semester 1) & $\mathrm{Rp}$ & $3,237,650$ & $\mathrm{Rp}$ & $4,307,000$ & $(1069350)$ \\
\hline 27 & & Rapat Bulanan & $\mathrm{Rp}$ & 655,800 & $\mathrm{Rp}$ & $1,479,000$ & $(823200)$ \\
\hline 28 & & Administrasi TU \& Pelaporan & $\mathrm{Rp}$ & 296,700 & $\mathrm{Rp}$ & 680,000 & $(383300)$ \\
\hline 29 & & Konsumsi Tamu & $\mathrm{Rp}$ & 581,000 & $\mathrm{Rp}$ & 780,000 & (199000) \\
\hline 30 & & Lain-lain & & & $\mathrm{Rp}$ & $1,668,500$ & $(1668500)$ \\
\hline 31 & & - Bola Futsal & $\mathrm{Rp}$ & 295,715 & $\mathrm{Rp}$ & $1,673,000$ & $(1377285)$ \\
\hline 32 & & Konsumsi Tamu & $\mathrm{Rp}$ & 581,000 & $\mathrm{Rp}$ & 938,000 & $(357000)$ \\
\hline 33 & & Buku Tatib dan Mutaba'ah Yaumiyah & $\mathrm{Rp}$ & $7,471,500$ & $\mathrm{Rp}$ & $7,900,000$ & $(428500)$ \\
\hline 34 & & Lain-lain & & & $\mathrm{Rp}$ & $4,333,000$ & (4333000) \\
\hline 35 & & Pelatihan /memenuhi undangan dinas/instansi & $\mathrm{Rp}$ & 850,000 & $\mathrm{Rp}$ & $1,025,000$ & (175000) \\
\hline 36 & & Administrasi TU \& Pelaporan & $\mathrm{Rp}$ & 290,000 & $\mathrm{Rp}$ & 560,000 & (270000) \\
\hline 37 & & Pembuatan Lab Komputer & $\mathrm{Rp} 2$ & $4,905,000$ & $\mathrm{Rp}$ & $28,400,000$ & (3495000) \\
\hline 38 & & Konsumsi Tamu & $\mathrm{Rp}$ & 581,000 & $\mathrm{Rp}$ & 765,600 & $(184600)$ \\
\hline 39 & & Transportasi kegiatan siswa dan guru & $\mathrm{Rp}$ & 508,400 & Rp & 675,000 & $(166600)$ \\
\hline 40 & & Lain-lain & & & $\mathrm{Rp}$ & 171,000 & $(171000)$ \\
\hline 41 & & Pelatihan /memenuhi undangan dinas/instansi & $\mathrm{Rp}$ & 850,000 & $\mathrm{Rp}$ & $1,714,000$ & $(864000)$ \\
\hline 42 & & Administrasi TU \& Pelaporan & $\mathrm{Rp}$ & 290,000 & $\mathrm{Rp}$ & 568,000 & (278000) \\
\hline 43 & & Fotocopy kegiatan sekolah & $\mathrm{Rp}$ & 581,000 & $\mathrm{Rp}$ & $1,063,000$ & $(482000)$ \\
\hline 44 & & Transportasi umum & $\mathrm{Rp}$ & 498,100 & $\mathrm{Rp}$ & 700,000 & $(201900)$ \\
\hline 45 & & Transportasi kegiatan siswa dan guru & $\mathrm{Rp}$ & 508,400 & $\mathrm{Rp}$ & 629,000 & (120600) \\
\hline 46 & I & Fotocopy kegiatan sekolah & $\mathrm{Rp}$ & 581,000 & $\mathrm{Rp}$ & $1,248,260$ & $(667260)$ \\
\hline 47 & ovemoer & Pembinaan yayasan & $\mathrm{Rp}$ & 500,000 & $\mathrm{Rp}$ & 815,000 & $(1315000)$ \\
\hline & & $\begin{array}{c}\text { Total defisit } 2017 \\
\text { Persentase penyimpangan } \\
\end{array}$ & $\operatorname{Rp} S$ & $2,886,815$ & & $\begin{array}{l}35,387,146 \\
146 \%\end{array}$ & $(40541831)$ \\
\hline
\end{tabular}

Berdasarkan tabel. 6 diatas menunjukkan hasil penyimpangan selama tahun 2017 sebesar $46 \%$ atau senilai dengan Rp. 40.541.831,00 dimana ada perubahan jika kita lihat di tahun 2016, sedangkan tahun 2017 lebih rendah dari hasil penyimpangannya. Kepala sekolah dan bendahara sekolah mulai mengunakan Management By Objective atau melakukan rencana berdasarkan tujuan dan lebih memanalisir keuangan dan lebih berhatihati dalam melakukan tindakan sehingga dana yang ditalangkan atau dipakai untuk kegiatan yang lain menjadi berkurang $180 \%$ total talangan dana atau penyimpangan selama 2 (dua) tahun sebessar $180 \%$.

Berdasarkan penjelasan diatas bahwa dalam penyimpangan ini ditemukan 
bahwa realisasi anggaran dan rencana kerja anggaran sekolah terdapat penyimpangan dalam bentuk penggantian pos setiap penyimpangan yang terjadi adalah sistem talangan dana yang mana dana yang surplus akan menutupi dana yang defisit selama itu dalam satu bulan sehingga realisasi yang ada tetap seimbang dan tercapai. Pada awalnya penyimpangan yang dilakukan dibolehkan oleh yayasan hanya saja bisa menutupi kekurangan yang ada sehingga dana yang surplus akan digunakan untuk menutupi anggaran yang mengalami defisit dan realisasi yang surplus akan dikumpulkan menjadi satu dan masuk ke akun lain-lain, akun ini mempunyai fungsi untuk keperluan di luar anggaran seperti undangan pernikahan, menjenguk karyawan sakit baik unit ataupun satu yayasan, dan takziah ke rumah murid, guru, dan karyawan yang dalam satu yayasan masih banyak fungsi lainnya.

Melihat hasil penelitian analisis realisasi anggaran dan rencana anggaran seharusnya pihak sekolah segera mengambil langkah yang cepat terhadap penyimpangan yang terjadi, apabila kejadian ini terus terulang akan berdampak tidak baiknya kinerja keuangan di SMPIT Al-Izzah. Di lihat dari sisi penggunaan anggaran yang terjadi surplus peneliti mengkaji walaupun dana yang digunakan memang untuk keperluan sekolah tetapi tetap saja ini tidak diperbolehkan, apalagi dari laporan 2 (dua) tahun yaitu tahun 2016 sampai 2017 hampir semuanya tidak sesuai rencana.

Menurut peneliti anggaran yang ada harus digunakan dengan semestinya sesuai dengan rencana atau budget yang telah ditetapkan dan digunakan sesuai dengan porsi yang ada sehingga rencana yang akan dilaksanakan akan berjalan sesuai apa yang diinginkan. Untuk pembuatan anggaran jika memang tidak digunakan setiap bulannya harus direvisi dan dirapatkan kembali kepada guru dan pegawai.

Penelitian ini sudah pernah dilakukan oleh Budi Sri Supeni pada tahun 2015 dengan judul Analisis Laporan Realisasi Anggaran dalam Pengelolaan RKAS di SMA Negeri 5 Madiun dengan hasil penelitiannya diperoleh data bahwa penyusunan RKAS di SMA Negeri 5 Madiun belum mengacu pada PP No. 19 Tahun 2005 tentang SNP, penggunaan sumber anggaran yang berkembang tiap tahun baik dari APBN, APBD Tk. I, APBD Tk. II maupun dari komite sekolah. Penelitian lainnya yang dilakukan oleh Sri Marliani pada tahun 2015 juga dengan judul Kesesuaian Rancangan Kegiatan dan Anggaran Sekolah (RKAS) dengan 
Laporan Pertanggungjawaban Tahun 2014/2015 di SD 2 Negeri Jati Kecamatan Binangun Kabupaten Cilacap, hasil penelitiannya diperoleh kesesuaian RKAS dengan laporan pertanggungjawaban di SD Negeri 2 Jati pada tahun ajaran 2014/2015 masih rendah, yang terdiri dari : (a) Program sekolah terdiri dari 90 kegiatan namun yang sesuai sebanyak 24 kegiatan; (b) Non program sekolah terdiri dari 8 kegiatan namun yang sesuai hanya 1 kegiatan. Jumlah keseluruhan ada 98 kegiatan dan yang sesuai dengan RKASnya hanya sebanyak 25 kegiatan.

\section{KESIMPULAN DAN SARAN}

A. Kesimpulan

1. Laporan realisasi rencana kerja anggaran sekolah di SMP Islam Terpadu Al-Izzah dengan membandingkan antara besarnya anggaran rencana kerja anggaran sekolah dengan realisasi anggaran dalam pelaksanaannya dua tahun terakhir ditemukannya perbedaan jumlah anggaran dan realisasinya ini disebabkan adanya pengalihan rencana kerja atau kegiatan-kegiatan yang ada, dan peneliti juga menemukan indikasi penggunaan anggaran yang termasuk penyimpangan antara lain : a. Penggunaan anggaran yang tidak sesuai dengan peruntukannya, khususnya pada dana rutin yang digunakan untuk menutupi kekurangan anggaran yang defisit.

b. Dana tidak dibelanjakan untuk anggaran yang sudah direncanakan.

c. Realisasi Anggaran pada Tahun 2016 sebesar $99 \%$ dan pada tahun 2017 sebesar 90\%, pengeolahan untuk anggaran tahun 2016 dan 2017 memiliki perbedaan antara rencana dengan realisasi anggaran peneliti menemukan bahwa anggara mengalami penurunan yang cuku besar yakni 9\% dari tahun sebelumnya, padahal biasanya tiap tahun harus ada peningkatan.

d. Angaran 2016 dan 2017 diketahui bahwa realisasi anggaran 2016 dua bulan anggaran yag tidak tercapai karena pengalihan pelaksanaan kegiatan dan untuk realisasi yang tercapai hanya sepuluh bulan jika dihitung persentase selama satu tahun mencapai 99\% ditahun 2016, ditahun 2017 realisasi anggaran yang tidak tercapai hanya delapan bulan karena tidak terjalannya kegiatan, pengalihan kegiatan, dan ratarata kegiatan banyak dialihkan ke semester 22018 dan empat bulan yang tercapai hingga $100 \%$ 
e. Perubahan bentuk format anggaran dan realisasi perlu adanya standar operasional prosedur yang jelas

f. Belanja anggaran sekolah yang tidak wajar dengan nilai yang ditetapkan sebelumnya.

B. Saran

1. Setiap bulan atau paling lama 3 bulan dilakukan evaluasi program atau kegiatan apa saja yang belum dilaksanakan sesuai dengan anggaran kas sehingga dapat mencapai realisasi sesuai target.

2. Dalam penyusunan RKAS harus memperhatikan jenis, obyek dan rincian obyek belanja yang akan dibutuhkan dalam suatu kegiatan sehingga realisasinya dapat mencapai $100 \%$

3. Diperlukan format anggaran baik laporan maupun realisasi yang sesuai dengan SOP.

4. Pencatatan keuangan harus menggunakan sebuah aplikasi seperti Zahir atau aplikasi keuangan lainnya agar semua laporan tersistem dan lebih mudah untuk dibuat

\section{DAFTAR PUSTAKA}

Achmad, Dedy Achmad Kerniady, dkk. (2015). Manajemen Pembiayaan Pendidikan. Bandung : PT Remaja Rosdakarya.

Arthaingan, H. Mutiha dan I Gusti Ketut Agung Ulupul. (2016). Akuntansi Sektor Publik Penerapan PSAK 45 Pada Universitas. Jakarta : Salemba Empat.

Arikunto, Suharsimin. (2013). Prosedur Penelitian Suatu Pendekatan Praktek. Jakarta : Renike Cipta.

Bastian, Indra. (2006). Akuntansi Pendidikan. Jakarta : Erlangga.

Fattah, Nanang. (2009). Ekonomi Dan Pembiayaan Pendidikan. Bandung : PT Remaja Rosdakarya.

Handoko, T. Hani. (2011). Manajemen. Yogyakarta : BPFE - Yogyakarta.

Ismaya, Bambang. (2015). Pengelolaan Pendidikan Bandung : PT Rafika Aditama.

Jae K. Shim, Joel dan G Siegel. (2000). Budgeting. Jakarta : Erlangga.

Maisah. (2013). Manajemen Pendidikan. Jambi : Referensi ( Gaung Persada Press Group ).

Marliyani, Septi. ( 2015 ) Kesesuaian Rancangan Kegiatan dan Anggaran Sekolah (RKAS) dengan Laporan Pertanggungjawaban Tahun 2014/2015 di SD Negeri 2 Jati Kecamatan Binangun Kabupaten Cilacap. [Online]. Tersedia:http://eprints.uny.ac.id/29480/ Tersedia (05 Februari 2018) 
Nafarin, M (2003). Penganggaran Perusahaan. Jakarta : Salemba Empat.

Nordiawan, Deddi , dan Ayuningtyas Hertianti. (2010). Akuntansi Sektor Publik. Jakarta : Selamba Empat.

Sri Supeni, Budi. 2015 https://digilib.uns.ac.id/dokumen/detail /50047/Analisis-Laporan-RealisasiAnggaran-dalam-Rencana-Kegiatandan-Anggaran Sekolah-Rkas-di-SmaNegeri-5 Madiun. [Online] Tersedia :

Syafri, Sofyan Harahap. (2001). Budgeting Peranggaran Perencanaan Lengkap Untuk Membantu Manajemen. Jakarta : PT Raja Grafindo Persada.

Suti'ah, H. Muhaimin dan Sugeng Listyo Prabowo. (2009). Manajemen Pendidikan Aplikasi dalam Penyusunan Rencana Kerja Anggaran Sekolah / Madrasah. Jakarta : Prenadamedia Group.

Subramanyam, K.R dan John J. Wild. (2012). Analisis Laporan Keuangan. Jakarta: Salemba Empat.

Sudaryono. (2016). Metode Penelitian Pendidikan. Jakarta : Prenadamedia Group.

Tim Dosen (Abubakar). (2013). Manajemen Pendidikan. Bandung : Alfabeta.

Welsch, Hilton Gordon. (2000). Anggaran Perencanaan dan Pengendalian Laba. Jakarta: Salemba Empat 
PROGRESS

Jurnal Pendidikan, Akuntansi dan Keuangan Universitas Banten Jaya
Vol 3 No. 2, Agustus 2020

E-ISSN 2622-7037 |P-ISSN 2623-0763 